\title{
Wavelength of Experimental LEDS: Hardness, Elastic Modulus, Degree of Conversion and Temperature Rise of a Microhybrid Composite
}

\author{
Ana Paula Bonilauri Ferreira ${ }^{a *}$, Paulo César Soares Júnior ${ }^{b}$, Evelise Machado Souza ${ }^{c}$, \\ Rodrigo Nunes Rached ${ }^{c}$, Sérgio Henrique Pezzin ${ }^{d}$, Sérgio Vieira ${ }^{c}$ \\ ${ }^{a}$ Departamento de Odontologia, Universidade da Região de Joinville - UNIVILLE, \\ Rua Paulo Malschitzki, 10, Sala A 102, Zona Industrial, CEP 89219-710, Joinville, SC, Brazil \\ ${ }^{b}$ Programa de Pós-graduação em Engenharia Mecânica, Pontifícia Universidade Católica do \\ Paraná - PUC-PR, Rua Imaculada Conceição, 1155, CEP 80215-901, Curitiba, PR, Brazil \\ 'Programa de Pós-Graduação em Odontologia, Pontifícia Universidade Católica do Paraná-PUC-PR, \\ Rua Imaculada Conceição, 1155, CEP 80215-901, Curitiba, PR, Brazil \\ ${ }^{d}$ Departamento de Quimica - Universidade do Estado de Santa Catarina, Centro de Ciências \\ Tecnológicas - CCT / Rua Paulo Malschitzki, s/n - Campus Universitário Prof. Avelino Marcante - \\ Bairro Zona Industrial Norte, CEP 89219-710, Joinville, SC, Brazil
}

Received: January 27, 2014; Revised: March 4, 2015

\begin{abstract}
The aim of this study was to evaluate the effect of different peak wavelengths $(450 \mathrm{~nm}, 468 \mathrm{~nm}$ and $490 \mathrm{~nm}$ ) of experimental LEDs on hardness, elastic modulus, degree of conversion and temperature rise of a microhybrid resin composite - Venus ${ }^{\circledast}$ (Heraeus Kulzer). Hardness and elastic modulus were determined by nanoindentation technique $(\mathrm{n}=5)$, degree of conversion was measured by FTIR $(n=5)$ and temperature rise was measured with a thermistor $(n=30)$. Data were submitted to ANOVA and multiple comparisons tests $(\alpha=0.05)$. Mechanical properties and degree of conversion $(p<0.001)$ were superior on the top surfaces of the specimens. $468 \mathrm{~nm}$ showed the highest mechanical properties values. There was no statistical difference in the degree of conversion $(\mathrm{p}=0.51)$ and in temperature rise ( $\mathrm{p}=0.06)$ among all LEDs. Hardness and elastic modulus were influenced by LED's wavelength, whereas degree of conversion and temperature rise were not influenced.
\end{abstract}

Keywords: laboratory research, composite resin, mechanical properties, degree of conversion, temperature rise, $L E D$, wavelength

\section{Introduction}

Composites are expected to reach a high degree of curing for adequate clinical performance ${ }^{1}$. When inadequately polymerized, composites can have their biological, physical and mechanical properties compromised ${ }^{2,3}$. As a result, marginal degradation and discoloration ${ }^{4}$, postoperative sensitivity and pulp irritation may occur ${ }^{1,5}$. The efficiency of polymerization depends on several factors, including those related to the material itself in terms of its composition ${ }^{1,6}$, and those related to the light-curing unit (LCU), such as light intensity, spectral distribution, thermal emission and exposure time ${ }^{7}$.

LED (Light Emitting Diode) LCUs are gradually replacing halogen LCUs because they have a longer lifetime, and the light flux is not compromised with time $e^{4,8}$. A suitable photoactivation process is of great importance to emit radiant energy at a specific wavelength ${ }^{9,10}$. The LEDs' spectral range is narrow and light is emitted with a wavelength near $470 \mathrm{~nm}^{3,8}$, matching the camphorquinone's peak ${ }^{3,11,12}$. Compared to halogen LCUs, LEDs thermal emissions are minimal ${ }^{8}$. This is of great clinical importance since excessive heat can be hazardous to the pulp ${ }^{13}$.

\footnotetext{
*e-mail: apbonilauri@gmail.com, ana.p@univille.net
}

One of the methods used to assess whether a composite is properly cured is a study of its hardness. Nanoindentation is one of the methods that can be used to determine not only the hardness but also the elastic modulus of the composite through curves of applied load and penetration on the specimen surface ${ }^{14,15,16}$. The efficiency of polymerization can also be evaluated by studying the degree of conversion (DC) ${ }^{4}$ which can be reached by Fourier Transform Infrared Spectroscopy (FTIR) $)^{3,4,17,18}$.

Several studies have been conducted focusing on the relationship between the energy density of LED LCUs and the degree of polymerization of composites ${ }^{17,19,20}$. However, there is little data about the performance of experimental LED LCUs with different wavelength peaks evaluated through DC, hardness and the elastic modulus of the cured composite. Moreover, authors found LED LCUs whose wavelength peak is below the optimum value for activation of camphorquinone $\mathrm{e}^{21,22}$.

The aim of this study was to evaluate the effect of different peak wavelengths of experimental LED LCUs on the hardness, elastic modulus, degree of conversion and temperature rise of a composite. Our hypothesis is that 
$468 \mathrm{~nm}$ peak wavelength will present the best values for the assessed properties.

\section{Material and Methods}

For this study, a Bis-GMA based microhybrid resin composite - Venus ${ }^{\circledR}$ (Heraeus Kulzer, GmBH, Wehrheim, Germany), A3 colour (batch 010125) was used.

A cylindrical steel mould of $4 \mathrm{~mm}$ in diameter and $2 \mathrm{~mm}$ thick was placed on a polyester strip and a glass slide was used to prepare the specimens. The mould was filled with the composite, and another polyester strip followed by another glass slide were placed over the filled mould. This process ensured the specimens were of a constant thickness and a standard distance from the tip of the curing light.

Using experimental LED LCUs (MMOptics, São Carlos, SP, Brazil) specifically developed for this study, the composites were photopolymerized immediately after their insertion into the mould. The power density of these LED LCUs was $350 \mathrm{~mW} / \mathrm{cm}^{2}$ and the energy density applied was $21 \mathrm{~J} / \mathrm{cm}^{2}$. LED LCUs wavelength calibrations were obtained from a spectrophotometer (USB 4000, Ocean Optics) which showed 450nm (L450), 468nm (L468) and 490nm (L490).

After curing, the specimens were removed from the mould and marked on their top surface. The specimens were stored for 48 hours in a dark container, at relative humidity of $100 \%$ at $37^{\circ} \mathrm{C}$. Before hardness and DC tests, the specimens were polished metallographically using silicon carbide discs of decreasing abrasiveness (400, 600, 800, 1200 grit). For the final polishing, special soft discs with diamond suspensions of decreasing grit size $(6 \mu \mathrm{m}, 3 \mu \mathrm{m}$, and $1 \mu \mathrm{m})$ were used, combined with a diamond paste. The specimens were then washed in running water to remove any residual particles. Ten specimens were prepared for each experimental LED, i.e. five for nanoindentation and five for FTIR. Temperature variation measurements were performed on 30 of the specimens prepared for each experimental LED.

Nanoindentation was used to assess the hardness and elastic modulus of the top and bottom surfaces of the specimens. Twenty-five indentations were performed on each surface of each specimen using a diamond Berkovich geometry indenter on a Nanoindenter XP(MTS System Corporation, Oak Ridge, TN, USA). Each indentation comprised a full loading and unloading cycle, with a maximum applied load of $400 \mathrm{mN}$ applied for 30 seconds. The hardness and elastic modulus were calculated from the load curves versus penetration by the Oliver and Pharr method ${ }^{23}$.

The DC of the specimens was measured by FTIR in reflectance mode, using an attenuated total reflectance accessory
(ATR) on a spectrometer (Spectrum One B, Perkin-Elmer, Beaconsfield, Bacon, UK), using 32 scans with a resolution of $4 \mathrm{~cm}^{-1}$ in the range of 4000 to $400 \mathrm{~cm}^{-1}$. Following that, the band from 1570 to $1670 \mathrm{~cm}^{-1}$ was scanned again to achieve better resolution in the region of interest. Spectral analysis was performed using Spectrum One software (Perkin-Elmer, Beaconsfield, Bacon, UK). Spectra were acquired from the top and bottom surfaces of the specimens.

The DC was determined by comparing the relative amount of aliphatic carbon double bonds $\left(1638 \mathrm{~cm}^{-1}\right)$ to the aromatic double bonds $\left(1609 \mathrm{~cm}^{-1}\right)$ of the polymerized and non-polymerized phases. The DC was calculated by the following Equation 1:

$$
D C(\%)=\left(1-\frac{\left[\begin{array}{l}
a b s(C=C \text { aliphatic }) \\
a b s(C=C \text { aromatic })
\end{array}\right] \text { of polymer }}{\left[\begin{array}{l}
a b s(C=C \text { aliphatic }) / \\
\text { abs }(C=C \text { aromatic })
\end{array}\right] \text { of monomer }}\right) \times 100
$$

Temperature variation was recorded from a thermistor connected to a multimeter. Temperature measurements started immediately after the resin composite $\left(20 \pm 0.5^{\circ} \mathrm{C}\right)$ was inserted in a teflon mould, and thereafter it was obtained every 2.5 seconds until it was polymerized for 60 seconds when the final temperature was recorded. The initial temperature was deducted from the final temperature in order to obtain the temperature variation $(\Delta \mathrm{T})$. All measurements were taken in controlled temperature environment $\left(20 \pm 1^{\circ} \mathrm{C}\right)$.

The mean values of hardness and elastic modulus of the top and bottom surfaces were subjected to two-way ANOVA, full factorial design, and Games-Howell parametric testing for multiple comparisons, considering the heterogeneous variances. The level of significance was $5 \%$. Statistical analysis was performed using SPSS 18.0 for Windows (SPSS Inc, Chicago, IL, USA).

The mean DC values of the top and bottom surfaces were subjected to two-way ANOVA, full factorial design, and Tukey HSD parametric testing for multiple comparisons, considering homogeneous variances. The level of significance was $5 \%$.

The temperature variation data was submitted to oneway ANOVA criterion. The level of significance was 5\%.

\section{Results}

The mean values of hardness, elastic modulus and hardness of the ratio between the bottom and top $(B / T)$ surfaces of the light-cured resin composite with different LED LCUs are shown in Table 1. The top surface presented higher values for the hardness and elastic modulus compared to

Table 1. Mean values (standard deviation) of hardness (GPa), elastic modulus (GPa) and hardness of ratio between the bottom and top $(\mathrm{B} / \mathrm{T})$ of evaluated resin composites.

\begin{tabular}{lcccc}
\hline & LED & Top & Bottom & B/T (\%) \\
\hline Hardness & $450 \mathrm{~nm}$ & $0.73(0.03) \mathrm{aA}$ & $0.44(0.02) \mathrm{aB}$ & $61(0.03) \mathrm{a}$ \\
& $468 \mathrm{~nm}$ & $0.76(0.04) \mathrm{bA}$ & $0.71(0.01) \mathrm{cB}$ & $94(0.06) \mathrm{c}$ \\
Elastic Modulus & $490 \mathrm{~nm}$ & $0.76(0.02) \mathrm{bA}$ & $0.50(0.03) \mathrm{bB}$ & $66(0.04) \mathrm{b}$ \\
& $450 \mathrm{~nm}$ & $13.09(0.37) \mathrm{aA}$ & $9.25(0.39) \mathrm{aB}$ & \\
& $468 \mathrm{~nm}$ & $13.87(0.58) \mathrm{bA}$ & $13.04(0.42) \mathrm{cB}$ & \\
& $490 \mathrm{~nm}$ & $13.70(0.44) \mathrm{bA}$ & $10.78(0.49) \mathrm{bB}$ & \\
\hline
\end{tabular}

Mean values followed by different lowercase in column and different uppercase in line exhibit significant differences, with a significance level of $5 \%$. 
Table 2. Mean values (standard deviation) of DC (\%) of evaluated resin composite.

\begin{tabular}{ccc}
\hline LED & Top & Bottom \\
\hline $450 \mathrm{~nm}$ & $69.40(6.06) \mathrm{aA}$ & $28.91(0.36) \mathrm{bB}$ \\
$468 \mathrm{~nm}$ & $64.40(6.18) \mathrm{aA}$ & $27.04(3.67) \mathrm{bB}$ \\
$490 \mathrm{~nm}$ & $63.33(2.92) \mathrm{aA}$ & $26.96(1.06) \mathrm{bB}$ \\
\hline
\end{tabular}

Mean values followed by different lowercase in column and different uppercase in line exhibit significant differences, with a significance level of 5\%.

Table 3. Mean increase (standard deviation) of temperature (degree Celsius) of each LED tested.

\begin{tabular}{cc}
\hline LED & Temperature variation $\left({ }^{\circ} \mathbf{C}\right)$ \\
\hline $450 \mathrm{~nm}$ & $1.89(0.27) \mathrm{a}$ \\
$468 \mathrm{~nm}$ & $1.71(0.36) \mathrm{a}$ \\
$490 \mathrm{~nm}$ & $1.87(0.36) \mathrm{a}$ \\
\hline
\end{tabular}

Mean values followed by same lowercase do not exhibit significance differences, with a significance level of $5 \%$.

the bottom surface $(\mathrm{p}<0.001)$. When only top surfaces were considered, L450 provided the lowest values for the hardness and elastic modulus $(\mathrm{p}<0.001)$. There was no significant difference between L468 and L490 on both the hardness $(p=0.87)$ and elastic modulus $(p=0.10)$. Considering the bottom surfaces, L468 generated the highest hardness and elastic modulus. Regarding B/T's hardness, L468 provided the highest value, followed by L490 and L450.

The mean values and standard deviation of DC are shown in Table 2. DC was significantly higher on the top surface compared to the bottom surface $(p<0.001)$, for all LED LCU. There were no significant differences among all LED LCUs tested on the top and bottom surfaces $(p=0.51)$.

Regarding temperature variation, there was no significant difference among the LEDs LCU tested $(p=0.06)($ Table 3$)$.

\section{Discussion}

The effectiveness of composite restorative procedures is directly dependent upon its polymerization. As curing equipments are fundamental in achieving this goal, several studies have focused on the irradiance of LEDs LCUs ${ }^{17,19,20}$. However, other variables such as the wavelength emitted by LED LCUs and temperature variation are also relevant in determining the efficiency of polymerization of resin composites.

In this study, different wavelength peaks influenced the polymerization of a resin composite differently. The lowest hardness and elastic modulus values were found on composite's bottom surface. Previous studies had also found similar results ${ }^{12,21,24,25}$. During photopolymerization, there is a considerable reduction of irradiance in deeper regions through the bulk of the composite, due to absorption and scattering of light by the resin matrix and particles filler ${ }^{25}$. This decrease in light results in reduced photons emission, interfering in the material's curing, and resulting in lower values for the mechanical properties tested.

The effectiveness of polymerization cannot only be measured by the hardness of the composite's top surface. Hardness of the bottom is mostly affected by light intensity, and is therefore considered a more accurate parameter for evaluating the effectiveness of curing ${ }^{24}$, and consequently the performance of the LCUs. Considering only the bottom surface, L468 generated the highest results for hardness and elastic modulus. Since the energy density was kept constant for the three LED LCUs, we could suggest the influence of the light's wavelength on the results. Previous studies report that not only the irradiance but also the wavelength of the emitted light has a direct effect on the degree of polymerization of resin composites ${ }^{12,21}$. According to Nomoto $^{11}$, the polymerization of composites is affected by light wavelength, $470 \mathrm{~nm}$ being the most efficient because it maximizes the camphorquinone activation ${ }^{1,10,19}$, which is the most commonly present photoinitiator in the composition of composites $^{26}$. If the composite photoinitiator does not absorb enough photons at an appropriate wavelength, polymerization may be impaired ${ }^{11}$. In this study, the blue light in different parts of the absorption spectrum of the camphorquinone produced different levels of curing efficiency. The wavelength closer to the absorption peak was more effective in polymerization, reflected by a higher hardness and elastic modulus. These same results were found in earlier studies ${ }^{27,28}$. Comparing different photoinitiators, Price et al. ${ }^{12}$ also reached the same conclusions. The LEDs LCU with a wavelength peak near $470 \mathrm{~nm}$ polymerized the composite more efficiently when the photoinitiator was camphorquinone.

The $\mathrm{B} / \mathrm{T}$ ratio of $\mathrm{L} 468$ demonstrates that the wavelength peak coinciding with the maximum spectral absorption of camphorquinone meant that there was a better composite depth of curing ${ }^{29}$. To considerer a composite's depth of cure to be adequate, the $\mathrm{B} / \mathrm{T}$ ratio should be greater than $80 \%{ }^{30}$. On the other hand, Torno et al. ${ }^{21}$ do not consider that the $\mathrm{B} / \mathrm{T}$ ratio alone is a good method to evaluate the polymerization effectiveness ${ }^{21}$. That is because if the composite is not properly cured but has a bottom hardness value similar to the top hardness value, the $\mathrm{B} / \mathrm{T}$ ratio can be greater than $80 \%$, and as such the deficient polymerization will be considered suitable.

Despite the low irradiance of experimental LEDs, the $\mathrm{DC}$ at the top of the composite was within the acceptable pattern, that is between 55 and $75 \%{ }^{31}$. Emami et al. ${ }^{32}$, Peutzfeldt \& Asmussen ${ }^{17}$ and Gritsch et al. ${ }^{22}$ showed that lower power densities can be compensated for by increasing the photopolymerization time, which increases the energy density, and thus induces a higher degree of polymerization. They justify this finding by the kinetics of polymerization, i.e. lower power densities and longer periods of time slow down the formation of a rigid polymer chain, which allows for more efficient polymerization. Continuous exposure to light helps maintain the activation of the camphorquinone molecules near to the surface ${ }^{24}$, increasing the material's degree of polymerization on top surface ${ }^{33}$. On the other hand, studies demonstrate that very high power densities applied in a shorter time do not increase the DC of composites ${ }^{32,34}$. The DC on the bottom surface of the composite was lower, which is consistent with other studies ${ }^{19,31,32}$. The DC was not influenced by the light wavelengths, either on the top or on the bottom of the resin composite.

This study did not find any association between hardness and DC. Although some studies have reported an association 
between hardness and $\mathrm{DC}^{35,36}$, others do not agree with this association $^{20,37}$. Ferracane ${ }^{36}$ and Obici et al. ${ }^{37}$ justify this result based on the fact that the mechanical properties of a resin composite are much more dependent on crosslinks density and on the quality of the polymer chain formed during polymerization reaction than in the DC itself. Increasing the exposure time of the composite to light can result in longer polymer chains with fewer crosslinks, thus not reducing the DC but only affecting its mechanical properties. Ferracane ${ }^{36}$ also adds that an absolute value for DC cannot predict an absolute value of hardness for all composites. Obici et al. ${ }^{37}$ conclude their study by pointing out that we should be cautious when hardness is considered as an indicator of DC. In some instances, composites with similar DC can present crosslinkings with different densities, which in turn can affect hardness.

The temperature variation generated by LED LCUs was low. The low power density of experimental LED LCUs can explain this finding, in agreement with results of other studies $^{2,13,27,38}$. Studies show that the higher the irradiance,

\section{References}

1. Aguiar FH, Braceiro A, Lima DA, Ambrosano GM and Lovadino JR. Effect of light curing modes and light curing time on the microhardness of a hybrid composite resin. The Journal of Contemporary Dental Practice. 2007; 8(6):1-8. PMid:17846665.

2. Rastelli ANS, Jacomassi DP and Bagnato VS. Effect of power densities and irradiation times on the degree of conversion and temperature increase of a microhybrid dental composite resin. Laser Physics. 2008; 18(9):1074-1079. http://dx.doi. org/10.1134/S1054660X08090132.

3. Rahiotis C, Patsouri K, Silikas N and Kakaboura A. Curing efficiency of high-intensity light-emitting diode (LED) devices. Journal of Oral Science. 2010; 52(2):187-195. http://dx.doi. org/10.2334/josnusd.52.187. PMid:20587941

4. Bala O, Ölmez A and Kalayci S. Effect of LED and halogen light curing on polymerization of resin-based composites. Journal of Oral Rehabilitation. 2005; 32(2):134-140. http:// dx.doi.org/10.1111/j.1365-2842.2004.01399.x. PMid:15641980

5. Hofmann N, Hugo B and Klaiber B. Effect of irradiation type (LED or QTH) on photo-activated composite shrinkage strain kinetics, temperature rise, and hardness. European Journal of Oral Sciences. 2002; 110(6):471-479. http://dx.doi. org/10.1034/j.1600-0722.2002.21359.x. PMid:12507222

6. Vandewalle KS, Roberts HW, Andrus JL and Dunn WJ. Effect of light dispersion of LED curing lights on resin composite polymerization. Journal of Esthetic and Restorative Dentistry. 2005; 17(4):244-254, discussion 254-255. http://dx.doi. org/10.1111/j.1708-8240.2005.tb00122.x. PMid:16231495

7. Rode KM, Freitas PM, Lloret PR, Powell LG and Turbino ML. Micro-hardness evaluation of a micro-hybrid composite resin light cured with halogen light, light-emitting diode and argon ion laser. Lasers in Medical Science. 2009; 24(1):87-92. http:// dx.doi.org/10.1007/s10103-007-0527-x. PMid:18058187

8. Carvalho FA, Almeida RC, Almeida MA, Cevidanes LH and Leite MC. Efficiency of light-emitting diode and halogen units in reducing residual monomers. American Journal of Orthodontics and Dentofacial Orthopedics. 2010; 138(5):617-622. http:// dx.doi.org/10.1016/j.ajodo.2008.10.023. PMid:21055603

9. Kurachi C, Tuboy AM, Magalhães DV and Bagnato VS. Hardness evaluation of a dental composite polymerized with the greater the heat generated by LCUs ${ }^{38,39,40}$. The authors also argue that LED LCUs have a narrow light spectrum and this causes the lower heat emission ${ }^{13,38}$. Not only are the emitted light spectrum and irradiance involved with a temperature increase, but also the exposure time, cavity depth $^{40}$ and chemical composition of resin composites ${ }^{21}$.

\section{Conclusions}

Hardness and elastic modulus were affected by the LED LCUs' wavelength, with the highest values for $468 \mathrm{~nm}$. However, both DC and temperature variations were not affected by the LED LCUs' wavelengths evaluated.

\section{Acknowledgements}

The authors thank the resin and LCUs manufacturers for providing the materials, the Nanostructured Materials Laboratory (Physics Department, UFPR) and the Polymer Laboratory (Materials Sciences and Engineering Program, UDESC) for their assistance.

experimental LED-based devices. Dental Materials. 2001; 17(4):309-315. http://dx.doi.org/10.1016/S0109-5641(00)000889. PMid: 11356207

10. Price RB, Labrie D, Rueggeberg FA and Felix CM. Irradiance differences in the violet $(405 \mathrm{~nm})$ and blue $(460 \mathrm{~nm})$ spectral ranges among dental light-curing units. Journal of Esthetic and Restorative Dentistry. 2010; 22(6):363-377. http://dx.doi. org/10.1111/j.1708-8240.2010.00368.x. PMid:21126292

11. Nomoto R. Effect of light wavelength on polymerization of light-cured resins. Dental Materials Journal. 1997; 16(1):6073. http://dx.doi.org/10.4012/dmj.16.60. PMid:9550002

12. Price RB and Felix CA. Effect of delivering light in specific narrow bandwidths from 394 to $515 \mathrm{~nm}$ on the micro-hardness of resin composites. Dental Materials. 2009; 25(7):899-908. http://dx.doi.org/10.1016/j.dental.2009.01.098. PMid:19243817

13. Atai $\mathrm{M}$ and Motevasselian F. Temperature rise and degree of photopolymerization conversion of nanocomposites and conventional dental composites. Clinical Oral Investigations. 2009; 13(3):309-316. http://dx.doi.org/10.1007/s00784-0080236-2. PMid:19085020

14. Mohamad D, Young RJ, Mann AB and Watts DC. Postpolymerization of dental resin composite evaluated with nanoindentation and microRaman spectroscopy. Archives of Orofacial Sciences. 2007; 2:26-31.

15. Willems G, Celis JP, Lambrechts P, Braem M and Vanherle G. Hardness and Young's modulus determined by nanoindentation technique of filler particles of dental restorative materials compared with human enamel. Journal of Biomedical Materials Research Part B: Applied Biomaterials. 1993; 27(6):747-755. http://dx.doi.org/10.1002/jbm.820270607. PMid:8408104

16. Drummond JL. Nanoindentation of dental composites. Journal of Biomedical Materials Research Part B: Applied Biomaterials. 2006; 78(1):27-34. http://dx.doi.org/10.1002/jbm.b.30442. PMid:16278844

17. Peutzfeldt A and Asmussen E. Resin composite properties and energy density of light cure. Journal of Dental Research. 2005; 84(7):659-662. http://dx.doi.org/10.1177/154405910508400715. PMid:15972597

18. Ferracane JL and Greener EH. The effect of resin formulation on the degree of conversion and mechanical properties of dental 
restorative resins. Journal of Biomedical Materials Research. 1986; 20(1):121-131. http://dx.doi.org/10.1002/jbm.820200111. PMid:3949822

19. Emami N and Söderholm KJ. How light irradiance and curing time affect monomer conversion in light-cured resin composites. European Journal of Oral Sciences. 2003; 111(6):536-542. http:// dx.doi.org/10.1111/j.0909-8836.2003.00082.x. PMid:14632692

20. Silva EM, Poskus LT, Guimarães JG, de Araújo Lima Barcellos A and Fellows CE. Influence of light polymerization modes on degree of conversion and crosslink density of dental composites. Journal of Materials Science. Materials in Medicine. 2008; 19(3):1027-1032. http://dx.doi.org/10.1007/s10856-007-3220-5. PMid:17665098

21. Torno V, Soares P, Martin JMH, Mazur RF, Souza EM and Vieira S. Effects of irradiance, wavelength, and thermal emission of different light curing units on the Knoop and Vickers hardness of a composite resin. Journal of Biomedical Materials Research Part B: Applied Biomaterials. 2008; 85(1):166-171. http:// dx.doi.org/10.1002/jbm.b.30929. PMid:17853418

22. Gritsch K, Souvannasot S, Schembri C, Farge P and Grosgogeat B. Influence of light energy and power density on the microhardness of two nanohybrid composites. European Journal of Oral Sciences. 2008; 116(1):77-82. http://dx.doi. org/10.1111/j.1600-0722.2007.00506.x. PMid:18186736

23. Oliver WC and Pharr GM. An improved technique for determining hardness and elastic modulus using load and displacement sensing indentation experiments. Journal of Materials Research. 1992; 7(6):1564-1583. http://dx.doi.org/10.1557/JMR.1992.1564.

24. Hubbezoğlu I, Bolayir G, Doğan OM, Doğan A, Ozer A and Bek B. Microhardness evaluation of resin composites polymerized by three different light sources. Dental Materials Journal. 2007; 26(6):845-853. http://dx.doi.org/10.4012/dmj.26.845. PMid: 18203490

25. Topcu FT, Erdemir U, Sahinkesen G, Yildiz E, Uslan I and Acikel C. Evaluation of microhardness, surface roughness, and wear behavior of different types of resin composites polymerized with two different light sources. Journal of Biomedical Materials Research Part B: Applied Biomaterials. 2010; 92(2):470-478. PMid:19957350.

26. Chen YC, Ferracane JL and Prahl SA. Quantum yield of conversion of the photoinitiator camphorquinone. Dental Materials. 2007; 23(6):655-664. http://dx.doi.org/10.1016/j. dental.2006.06.005. PMid:16859741

27. Rastelli ANS, Jacomassi DP and Bagnato VS. Degree of conversion and temperature increase of a composite resin light cured with an argon laser and blue LED. Laser Physics. 2008; 18(12):15701575. http://dx.doi.org/10.1134/S1054660X0812030X.

28. Jandt KD, Mills RW, Blackwell GB and Ashworth SH. Depth of cure and compressive strength of dental composites cured with blue light emitting diodes (LEDs). Dental Materials. 2000; 16(1):41-47. http://dx.doi.org/10.1016/S0109-5641(99)00083-4. PMid:11203522
29. Ramp LC, Broome JC and Ramp MH. Hardness and wear resistance of two resin composites cured with equivalent radiant exposure from a low irradiance LED and QTH light-curing units. American Journal of Dentistry. 2006; 19(1):31-36. PMid:16555655.

30. Pilo R and Cardash HS. Post-irradiation polymerization of different anterior and posterior visible light-activated resin composites. Dental Materials. 1992; 8(5):299-304. http:// dx.doi.org/10.1016/0109-5641(92)90104-K. PMid:1303371

31. Lohbauer U, Zinelis S, Rahiotis C, Petschelt A and Eliades G. The effect of resin composite pre-heating on monomer conversion and polymerization shrinkage. Dental Materials. 2009; 25(4):514-519. http://dx.doi.org/10.1016/j.dental.2008.10.006. PMid:19081616

32. Emami N, Söderholm KJ and Berglund LA. Effect of light power density variations on bulk curing properties of dental composites. Journal of Dentistry. 2003; 31(3):189-196. http:// dx.doi.org/10.1016/S0300-5712(03)00015-0. PMid:12726703

33. Alpöz AR, Ertugrul F, Cogulu D, Ak AT, Tanoglu M and Kaya E. Effects of light curing method and exposure time on mechanical properties of resin based dental materials. European Journal of Dentistry. 2008; 2(1):37-42. PMid:19212507.

34. Feng L, Carvalho R and Suh BI. Insufficient cure under the condition of high irradiance and short irradiation time. Dental Materials. 2009; 25(3):283-289. http://dx.doi.org/10.1016/j. dental.2008.07.007. PMid:18760834

35. Vandewalle KS, Ferracane JL, Hilton TJ, Erickson RL and Sakaguchi RL. Effect of energy density on properties and marginal integrity of posterior resin composite restorations. Dental Materials. 2004; 20(1):96-106. http://dx.doi.org/10.1016/ S0109-5641(03)00124-6. PMid:14698779

36. Ferracane JL. Correlation between hardness and degree of conversion during the setting reaction of unfilled dental restorative resins. Dental Materials. 1985; 1(1):11-14. http:// dx.doi.org/10.1016/S0109-5641(85)80058-0. PMid:3160625

37. Obici AC, Sinhoreti MAC, Frollini E, Sobrinho LC and Consani S. Degree of conversion and Knoop hardness of Z250 composite using different photo-activation methods. Polymer Testing. 2005; 24(7):814-818. http://dx.doi.org/10.1016/j. polymertesting.2005.07.011.

38. Asmussen E and Peutzfeldt A. Temperature rise induced by some light emitting diode and quartz-tungsten-halogen curing units. European Journal of Dentistry. 2005; 113(1):96-98. http:// dx.doi.org/10.1111/j.1600-0722.2004.00181.x. PMid:15693836

39. Kleverlaan CJ and de Gee AJ. Curing efficiency and heat generation of various resin composites cured with high-intensity halogen lights. European Journal of Dentistry. 2004; 112(1):84-88. http:// dx.doi.org/10.1111/j.0909-8836.2004.00101.x. PMid:14871198

40. Schneider LF, Consani S, Correr-Sobrinho L, Correr AB and Sinhoreti MA. Halogen and LED light curing of composite: temperature increase and Knoop hardness. Clinical Oral Investigations. 2006; 10(1):66-71. http://dx.doi.org/10.1007/ s00784-005-0028-x. PMid:16402230 